\title{
PROMOTION OF APPROPRIATE USE OF ELECTRONIC DEVICES AMONG HONG KONG ADOLESCENTS
}

\author{
Catherine K. Y Kwong, Ben Y. F Fong \\ The Hong Kong Polytechnic University \\ Correspondence: yffong@speed-polyu.edu.hk
}

\begin{abstract}
The advancement of technology is changing the world so rapidly with implication to people's daily activities and health. The excessive utilisation of electronic devices, particularly among adolescents, are affecting the physical, psychological and social wellbeing of these young people. Physical inactivity, obesity, musculoskeletal conditions, vision, cognitive development, sleep pattern, family relationship, addiction and gaming are issues of importance and attention arising from the inappropriate use of electronic devices. Stakeholders, including the parents, teachers, government, community organisations and the adolescents themselves, have different but complementary roles in the prevention of internet addiction and in the promotion of appropriate use of electronic devices among adolescents.
\end{abstract}

\section{KEYWORDS}

electronic devises, screen devices, internet addition, adolescents

\section{INTRODUCTION}

The explosive development of technology in recent decades is clearly manifested through the use of electronic devices including computers, smartphones, tablets computers, and other entertainment products. With the help of computer and the Internet, many tasks in our daily life are becoming easier, quicker and more convenient in different aspects, especially for adolescents. Electronic devices with online function bring lots of benefits and advantages to them in academic studying, literature research, sharing ideas and expressing their feelings in social media, and enjoyment as well. However, the improper use of technology and electronic screen products have also induced health attention to problems associated with excessive use. [1] Some undesirable adverse effects affecting teenagers arising from the addiction in using the electronic devices are, for example, academic failure, problems in interpersonal relationships, absenteeism, and antisocial behaviours. [2] In this review, the current situation of the prevalence of electronic devices among Hong Kong teenagers and the existing practical plans in the promotion of appropriate use of electronic devices among different parties are discussed.

\section{BACKGROUND}

In Hong Kong, a large proportion of adolescents have online activities. A Thematic Household Survey performed by the Census and Statistics Department (2017) studied the use of personal computer (PC) and Internet penetration in households has shown that the percentage of the usage of the Internet among people over 10-year-old increased from $87.5 \%$ in 2016 to $89.4 \%$ in 2017 . Almost all persons in the age group 10 to 24 had the knowledge of using PC, and that they had online activities during the 12 months before the survey. [3]

Smartphones are the typical communication tool in our daily life. Many people use the phones all the time playing electronic games on buses, Mass Transit Railway MTR and even when walking on the street. Smartphone obsession is so common in public places that it has earned the users a phrase, 'bowed head tribe'. The popular usage of smartphone among Hong Kong people has been increasing over the past few years. Nearly 5.7 million of 
people aged 10 and over had their own smartphone in 2017, 2.3 million more compared with that in 2012. The popularity of using smartphone increased from $54.0 \%$ in 2012 to $88.6 \%$ in 2017 . [3]

To determine the definition of excessive use, the time spent online can be one of the indicators, but it may be differentiated by considering the personal habit on the Internet use and the social environment. In a French exploratory study in 2011, discovered that time spent online was correlated to Internet addiction, but the cut-off of an at-risk amount of time online was hard to define because of many other interacting factors. [4]

\section{RISK FACTORS}

In order to prevent the problem in adolescents, it is essential to lower the possibility of risk factors and enhance the related protective methods simultaneously. Hence, it is important to understand both risk and protective factors in the development of internet addiction.

The first predictor related to electronic addiction is age. Adolescents and young adults have a higher chance of becoming internet addicts when compared with those in other age groups. Adolescents are undergoing the process of personality and psychological development. They want to develop a personal identity and to secure peers' acceptance. They need to build up intimate relationship with friends and classmates, so that they can easily get access to the Internet with them either at home or in school. They easily develop Internet addiction behaviours. [5]

Gender is the second predictorfactor related to internet addiction. There are a significantly higher number of male internet addicts than there are of females, although there is a growing number of females in excessive internet use. [5]

The unstable parental marital status is another risk factor. It was reported that internet addiction was more common among adolescents who grew up in single-parent families, and who had more parent-child conflicts or interparental conflicts. Therefore, teenagers who live in a family with parental dissension may present with more behavioural problems such as internet addiction. [5]

\section{CONSEQUENCES}

The more time spent on electronic devices, the less time will be available for doing exercises and for interpersonal interactions, resulting in a higher risk in children's growth and mental health. The most obvious impacts of overuse of electronic devices involve three areas, including physical, psychological and social aspects.

\section{PHYSICAL INACTIVITY AND OBESITY}

Adolescents are more willing to spend time using electronic devices over physical activity. Childhood obesity and insufficient physical fitness may result from that physical inactivity. Sedentary activities can disrupt healthy eating habits as children tend to eat snack food with high sugar or high calories when they are sitting down to play games. It may lead to higher energy intake which may further give rise to overweight problem. Students who spend more than two hours of screen time per day have a higher chance (two times) of getting overweight or obese than peers who spend less than one hour daily. [6] A study conducted by the University of Hong Kong has shown that kids who spend additional time on playing electronic entertainment apparatus are more likely to result in being overweight. [7]

Excessive time on electronic devices reduces the chances for children to do physical exercises and outdoor activities, and this may affect their health and physical development. [6] In a study in 2017, the percentage of students who had fulfilled the WHO's recommendations on at least 60 minutes of moderate to vigorous intensity exercising daily was only about $8 \%$ and $4 \%$ in primary and secondary school students respectively. These are extremely low rates (Department of Health, 2018). According to the data from the School Physical Fitness Award Scheme in 2016 and 2017, it was found that Hong Kong students had a pretty poor performance in the flexibility, muscle energy, and cardiorespiratory fitness when compared with students in China, Singapore, and European countries. [7]

\section{MUSCULOSKELETAL PROBLEMS}

People usually ignore proper posture when using electronic products, leading to increased risk of suffering from neck ache, back pain and upper limbs soreness. [6] The Hong Kong Polytechnic University (PolyU) and the Hong Kong Physiotherapy Association had conducted joint research in 2013 with 582 students aged between 10 to 15. 84\% students were regular users of smartphone, $76 \%$ were 
desktop computer users and $31.6 \%$ were tablet computer users. $30 \%$ students reported that they spent 1 to 4 hours every day on their smartphone while $27.6 \%$ were suffering from discomforts related to overuse of electronic devices. Among the students who were suffering some pain, nearly $80 \%$ had neck pain, $30 \%$ had shoulder pain, and $51 \%$ experienced wrist and finger pain. [8]

\section{VISION}

Computer screens, smartphones, and tablet screens are sources of blue light, which can decrease contrast, leading to digital eye strain. Blue light can transmit through the cornea and the crystalline lens and reaches the retina. Exposing to excess of blue-violet light for a long period of time is hazardous to the human retina. [9] Prolonged usage of electronic devices is associated with Computer Vision Syndrome (CVS), of eye and vision-related problems. The most common symptoms are dry eyes, eye strain, blurred vision, neck and shoulder pain and headache. [6]

\section{SLEEP DEPRIVATION}

Sleep is a vital element in children's physical and psychological development. Deficient sleep quantity or poor sleeping quality is a general health concern with deleterious health effects. Electronic devices especially computers and portable mobiles are becoming an indispensable component in children's life and may affect their sleep duration and quality. [10] Children who use mobile devices at bedtime are twice as likely to sleep less than nine hours at night. In a study, $45.4 \%$ of children reported that they have insufficient sleep when using the devices just before bedtime and $52 \%$ children claimed that they have poor sleeping quality when using a mobile device before going to bed. [10] Among Hong Kong students, the 2017 study found that there was $10.2 \%$ increase in deprived sleep time among primary school students who reported adverse effects of electronic screen products use. [11]

\section{COGNITIVE DEVELOPMENT}

Some studies have found the definite correlation between over use of electronic devices and Attention-Deficit Hyperactivity Disorder (ADHD). [12] The study from HKU has shown that children who spent more time on electronic devices were more probably having behavioural problems including emotional and hyperactivity, with poor academic performance. The study has also indicated that the positive relation between screen time and risk of $A D H D$ among the primary school children. [7]

\section{FAMILY RELATIONSHIP}

The relationship of parent and child would be affected and is due to a conflict between two parties on the issue of using the electronic devices. According to the survey from the Department of Health in 2017, there was a double-digit increment (11.5\%) in the percentage of quarrelling with parents about using the Internet and electronic screen products among primary school children compared with that in 2014 . Over $70 \%$ of parents had arguments with their children because of the use of electronic devices. [11]

\section{ADDICTION AND GAMING DISORDER}

Since 2013, "Internet Gaming Disorder" has been included in the classification of mental and behavioural disorders of the American Psychiatric Association. Gaming Disorder, with its online and offline variants, was defined in the 11 th Revision of the International Classification of Diseases (ICD11) in 2018 by World Health Organization as a pattern of gaming behaviour that results in noticeable problem or significant impairment in personal, family, social, educational or occupational performance (WHO, 2018). It can be recognized and has clinically significant syndrome associated with distress or affected personal development as a result of repetitive gaming behaviour. [13] This addiction is more prevalent in people aged below 30, and more common in younger teenagers below 19. [12]

\section{ROLES OF STAKEHOLDERS}

Although currently there are no empirically-based control management for internet addiction, all the related stakeholders have their corresponding responsibilities in the prevention of problematic use in electronic devices and in promoting the appropriate use of such devices among adolescents.

\section{PARENTS}

Parents have their specific roles in coping with this issue. Since they are close family members, they are expected to be a motivator to help the children by encouraging them to establish a healthy habit on the Internet and maintain a balance between their cyber activities and social livelihood. They should demonstrate a role model to their children the correct approach in behaviour, and even the 
right attitude in using electronic devices. For primary school students, parents are advised to give clear instructions and set requirements to limit the time of use after an agreeable conversation with their children. The increase in the amount of time spent in face-to-face interactions between adults and children can result in better social skills and good quality relationships overall. Parents are also recommended to help their children to explore other interests in physical activities in order to reduce the reliance on electronic entertainments and develop a healthy relationship with peers in their school life. [6]

For adolescent students, their impulsive personality means that they are willing to take part in risk taking behaviours. They learn to do the task independently, but they need others assurance of their own worth and are also desirous in socialization. Thus, parents must guide and coach them through daily life skill trainings, to enhance their strength and ability in identifying the potential risks and in developing skills in the proper use of electronic tools. [6]

\section{TEACHERS}

Educators perform similar duties as parents in the use of electronic devices. They both give guidance and supports for the students. For junior students, teachers need to educate and explain to children about the possible risks in using the electronic screening products in order to lower their opportunity of being trapped in the Internet. For senior students, teachers should communicate with them with a positive and caring attitude. For the purpose of maintaining a harmonious atmosphere between teachers and students, sharing self-experiences in complementary communication with each other enhances mutual understanding and performs a concordant relationship. Trust and respect to the students on the usage will help them to avoid the dependence on the electronic devices. [6]

\section{SCHOOLS}

Schools are very important in health promotion in terms of health education and personal development in school curriculum. More physical activities are recommended for the primary and secondary students. The study from HKU reported that the School Physical Fitness Award Scheme was an effective strategy to promote physical activity and fitness to students. The sports mentorship programme helps improving the muscular development and mental health of youth. Schools should take a passionate role in helping children to do more physical activity meeting the recommended standard in physical activity of WHO, besides sitting and learning at classrooms to reduce the risk of getting overweight among the students. [7]

\section{GOVERNMENT DEPARTMENTS}

The Government plays the key role in health promotion with its powerful capacity in funding research, and providing expertise, innovation, education and environmental supports. Major working areas of the Government include policy leadership, needs assessment, resources planning, organizing community activities and outcomes measurement.

\section{DEPARTMENT OF HEALTH}

The Department of Health has the main responsibility in disease prevention and health promotion to the general public. It carries out major duties in different routines such as summarizing relevant and updated information of the common health issues. In the problem of excessive Internet use, several guidelines have been produced for various groups of people including adolescents, parents and teachers on how to reduce the time spent on the electronic devices without the reliability on the screen products. It has organized diverse health promotion projects, for instance "Change for Health" and "Start Smart Parent Guide". It also publishes educational articles and newsletters regarding the proper usage of electronic devices. Moreover, the Student Health Service of the Department usually organizes talks for adolescents and parents e.g., 'Balance in Net' and 'Never Lost in Net Again'. [1]

\section{EDUCATION BUREAU}

The Educational Bureau has noted the potential health impacts of increased time spent on electronic devices in adolescents. It promotes anti-cyberbullying campaigns for students as a part of the school curriculum and provides teachers with training programmes on topics of cybersafety. It also gives comprehensive advice on the appropriate use of computer and e-books at schools. Besides, its cooperation with selected NGOs it helps to provide counselling services to students, parents and teachers. It also collaborates with the Information Technology sectors to introduce the importance of Internet safety and proper use of mobile screening products to the students. [1] 


\section{NON-GOVERNMENTAL ORGANIZATIONS}

Non-Governmental Organizations (NGOs) play an essential function in community education through health services, research, workforce development and advocacy. They are dedicated to help parents and the youth, by providing information and advice, counselling, group therapies and individual case management. [14] For example, the Tung Wah Group of Hospitals offers talks, workshops and treatment group to enhance public awareness and promote healthy family life with balanced lifestyle. The 'Say No to Cyber Addiction' Project is targeted for adolescents who are having high risk of internet addiction, youth workers, teachers, and parents. They cultivate adolescents' healthy attitude on internet surfing, strengthen their selfcontrol on internet surfing and awareness of internet safety. They also provide support in strengthening parents' and teachers' knowledge and skills on handling adolescents' internet behaviours. [15]

The Hong Kong Christian Service, another NGO, have been providing the Online New Page Online Addiction Counselling Centre to young internet addicts starting from 2005. They hold activities such as workshops, consultation service, supporting and sharing sessions, outreaching services and professional training, to rebuild and develop effective strategies and skills to regain the life balance of young internet addicts and to help parents of young internet addicts in improving family functioning. They also aim to promote the messages of healthy internet use through community education. [16]

There are some additional programmes offered by other organizations to help with the internet addiction problems among adolescents. The Hong Kong Council of Social Service provides an Internet Learning Resource Platform 'WebOrganic' for low-income group students, through implementing activities in promoting safe Internet usage during learning and searching information. [17] Moreover, the "Game Over Programme" designed by the Department of Psychology in the University of Hong Kong is an effective scheme for prevention of game addiction among Hong Kong primary school students. [18]

\section{ADOLESCENTS}

Teenagers have their own responsibility and actions to protect themselves in avoiding Internet addiction. They should learn to be self-protector in considering their health within the settings of their own daily life. They must understand that technology and electronic devices at the school are mainly used for learning purposes, and not designed for other personal uses, such as installing games or playing on student computers. [19] They should make good use of the devices in reading e-books during in-class lessons or completing homework in online platforms. They should not spend too much time in entertainment or game competitions. They should be wiser in searching their own interests so as to create a balanced life with enough physical activity. Developing technological skills, health knowledge, and self-discipline in using the new technologies can help them to keep aware of the risks of the excessive digital devices use. When encountering problems, they are encouraged to share their feeling, problems and thoughts with reliable adults, e.g. parents and teachers, through an open and effective communication. [6]

\section{CONCLUSIONS}

It is an undeniable fact that the booming development of electronic devices in this 21 st century gives us a wide range of benefits. At the same, we need to consider the drawbacks of excessive use and addiction problems. Every stakeholder should take their responsible actions and work in collaboration with each other to safeguard the health of the young generation. Teachers and parents are responsible for guidance and education. Government departments act as scheme promoters. NGOs are the executors to provide social supports for the needy adolescents. Furthermore, teenagers should self-protect themselves and self-control from the electronic enticement. We should create an active and open platform for discussing and pondering the safe and proper ways in using electronic devices. Hence, the target of lowering the prevalent dependence on digital screen products among adolescents in Hong Kong this can be achieved through the promotion of appropriate use of electronic devices and the participation and contribution in supporting activities by various groups and stakeholders.

\section{References}

1. World Health Organisation. Public health implications of excessive use of the Internet, computers, smartphones and similar electronic device: Meeting report 5-6. 2015; Appendix C: 64-69

2. Akar F. Purposes, causes and consequences of excessive internet use among Turkish adolescents. Eurasian Journal of Educational Research. 2015; 60:35-56. 
3. Census and Statistics Department, Hong Kong Special Administrative Region. Thematic Household Survey Report No. 64 [Internet]. 2018, March [cited 2019 Feb 1];2:1 1-12. Available from:

https://www.statistics.gov.hk/pub/B1 1302642018XXXXB010 0.pdf

4. Achab S, Nicolier M, Mauny F, Monnin J, Trojak B, Vandel $\mathrm{P}$, et al. Massively multiplayer online role-playing games: comparing characteristics of addict vs non-addict online recruited gamers in a French adult population. BMC Psychiatry. 2011;11:144.

5. Shek DTL, Yu L. Internet addiction in Hong Kong adolescents: profiles and psychosocial correlates. Int J Disabil Hum Dev. 2012; 11 (2):133-142.

6. Student Health Service, Department of Health. Report of Advisory Group on Health Effects of Use of Internet and Electronic Screen Products [Internet]. 2014 [cited 2019 Feb 1]. Available from:

https://www.studenthealth.gov.hk/english/internet/report/ files/e_report.pdf

7. Li Ka Shing Faculty of Medicine, The University of Hong Kong. HKU Studies Reveal Hong Kong Children Overuse Digital Devices and Have Inferior Physical Fitness. Press Release [Internet]. 2017 [cited 2019 Feb 1]. Available from: https://www.med.hku.hk/news/press/hku-studies-revealhong-kong-children-overuse-digital-devices-and-haveinferior-physical-fitness

8. The Hong Kong Polytechnic University. PolyU expert studies the health effects of using portable electronic devices. Media Releases [Internet]. 2013 Sept 01 [cited 2019 Feb 1]. Available from:

https://www.polyu.edu.hk/web/en/media/media_release s/index_id_2595.html

9. Pardhan S, Sapkota RP. Eye complications of exposure to ultraviolet and blue-violet light. International Review of Ophthalmic Optics [Internet]. 2016, September [cited 2019 Feb 1]. Available from:

http://www.pointsdevue.com/article/eye-complicationsexposure-ultraviolet-and-blue-violet-light\#

10. Carter B, Rees P, Hale L, Bhattacharjee D, Paradkar MS. (ember). Association Between Portable Screen-Based Media Device Access or Use and Sleep Outcomes - A Systematic Review and Meta-analysis. JAMA Pediatrics. 2016 Dec; 170(12):1202-1208.

11. Department of Health. Case Study on Policy and Programme Responses to Public Health Problems Associated with Excessive Use of Internet and Other
Communication and Gaming Platforms - An Overview of Situation in Hong Kong [Internet]. 2018 Feb 8 [cited 2019 Feb 1]. Available from:

https://www.studenthealth.gov.hk/tc_chi/internet/files/he althy_use_of_internet_ppt_8_feb_2018.pdf

12. Jiang B, Schmillen R, Sullivan WC. How to Waste a Break: Using Portable Electronic Devices Substantially Counteracts Attention Enhancement Effects of Green Spaces. SAGE Journals. [Internet]. 2018 July 16 [cited 2019 Feb 1]. Available from:

https://journals.sagepub.com/doi/pdf/10.1177/001391651 8788603

13. Wu LL. Are our smart phones affecting our mental health? World Health Organization New Release [Internet]. 2018 Mar 28 [cited 2019 Feb 1]. Available from: http://www.who.int/china/news/detail/28-03-2018-areour-smart-phones-affecting-our-mental-health-

14. Centre for Health Protection. Non-Communicable Disease Watch - Trapped in the Net [Internet]. 2013 July [cited $2019 \mathrm{Feb}$ 1]. Available from:

https://www.chp.gov.hk/files/pdf/ncd_watch_jul2013.pdf

15. Tung Wah Group of Hospitals. Integrated Centre on Addiction Prevention and Treatment (Integrated Treatment Services for Multi-addiction and comorbid Mental Health Problems) [Internet]. 2018 [cited 2019 Feb 1]. Available from: http://www.tungwahcsd.org/en/ourservices/youth-and-family-services;category/9

16. Hong Kong Christian Service. Online New Page-Online Addiction Counselling Centre [Internet]. 2016 [cited 2019 Feb 1]. Available from: http://www.hkcs.org/en/services/online

17. Centre for Health Protection. Non-Communicable Diseases Watch - Use of Internet and Electronic Screen Products among Children and Adolescents [Internet]. 2015 Jan [cited 2019 Feb 1]. Available from: https://www.chp.gov.hk/files/pdf/ncd_watch_jan2015.pdf 18. The University of Hong Kong. "Survey on the Gaming Habits among Hong Kong Upper Primary Students" major findings and conclusion. Press Release [Internet]. 2017 Jun 20 [cited 2019 Feb 1]. Available from: https://www.hku.hk/f/upload/16490/170620_attached_e.p df

19. Park M. Best Practices for Appropriate Use of Technology. Kentucky Department of Education [Internet]. 2018 May 22 [cited 2019 Feb 1]. Available from: https://education.ky.gov/districts/tech/Pages/BestAppropriate-Use.aspx 